\title{
Plasma YKL-40 as a biomarker for bevacizumab efficacy in patients with newly diagnosed glioblastoma in the phase 3 randomized AVAglio trial
}

\author{
Mogens K. Boisen ${ }^{1}$, Camilla B. Holst ${ }^{2}$, Nicola Consalvo ${ }^{3}$, Olivier L. Chinot ${ }^{4}$ and Julia \\ S. Johansen ${ }^{1,2,5}$ \\ ${ }^{1}$ Department of Oncology, Herlev University Hospital, Herlev and Gentofte Hospital, Copenhagen, Denmark \\ ${ }^{2}$ Department of Medicine, Herlev University Hospital, Herlev, and Gentofte Hospital, Copenhagen, Denmark \\ ${ }^{3}$ Biostatistics, F. Hoffmann-La Roche Ltd, Basel, Switzerland \\ ${ }^{4}$ Department of Neuro-Oncology, Aix-Marseille University, Marseille, France \\ ${ }^{5}$ Institute of Clinical Medicine, Faculty of Health and Medical Sciences, University of Copenhagen, Copenhagen, Denmark
}

Correspondence to: Mogens K. Boisen, email: mogens.karsboel.boisen@regionh.dk

Keywords: bevacizumab; YKL-40; newly-diagnosed; glioblastoma; AVAglio

Received: May 07, 2017

Accepted: November 14, 2017

Published: December 04, 2017

Copyright: Boisen et al. This is an open-access article distributed under the terms of the Creative Commons Attribution License 3.0 (CC BY 3.0), which permits unrestricted use, distribution, and reproduction in any medium, provided the original author and source are credited.

\section{ABSTRACT}

YKL-40 is a glycoprotein with pro-angiogenic functions. We hypothesized that patients with newly diagnosed glioblastoma and low baseline plasma YKL-40 levels derive greater benefit from first-line bevacizumab. Plasma samples were collected from 563 patients in the randomized, phase 3 AVAglio trial who received bevacizumab or placebo plus radiotherapy/temozolomide. Raw plasma YKL-40 concentrations were converted to age-corrected percentiles of normal healthy YKL-40 levels and divided into quartiles ( $Q$ ). The impact of baseline plasma YKL-40 level on survival was investigated using Cox regression analyses. Patients with low baseline plasma YKL-40 ( $\leq$ Q1) had an improved progression-free survival hazard ratio (HR) for bevacizumab versus placebo $(0.37,95 \%$ confidence interval $[\mathrm{CI}]: 0.25-0.55)$ compared with high plasma YKL-40 (> Q1) (0.71, 95\% CI: 0.57-0.87). Overall survival HRs were comparable between the subgroups ( $\leq$ Q1: 0.69, 95\% CI: 0.44-1.09; ( $>$ Q1: 0.88, 95\% CI: 0.68-1.13). A trend for improved progression-free survival HR with low versus high YKL-40 was observed in proneural glioblastoma (0.41, 95\% CI: 0.13-1.28 vs 0.80 , 95\% CI: $0.45-1.40$, respectively), but not for proliferative/mesenchymal subtypes. Elevated plasma YKL-40 ( $>$ 90th percentile of normal) was an independent negative prognostic factor. In conclusion, the predictive value of baseline plasma YKL-40 level as a biomarker for bevacizumab efficacy in glioblastoma may be limited to patients with proneural tumors. Independent validation studies are required to confirm these results.

\section{INTRODUCTION}

CHI3L1 (Chitinase-3-like protein 1) is one of the most overexpressed genes in glioblastomas, relative to normal brain and low-grade gliomas [1]. CHI3L1 is a marker for the mesenchymal subtype of glioblastoma and is related to extracellular-signal-regulated kinases and protein kinase B phosphorylation [2]. YKL-40, which is encoded by the CHI3L1 gene, is produced by tumor cells, inflammatory cells, and stem cells [3-5]. YKL-40 interacts with the receptors IL-13R $\alpha 2$ [6], CRTH2 [7], RAGE [8], syndecan-1 [9], and PAR-2 [10], but its function is not completely known. YKL-40 induces vascular endothelial growth factor (VEGF) expression and both YKL-40 and VEGF are pro-angiogenic factors associated with tumor angiogenesis [11-17]. In vitro, YKL-40 up-regulates VEGF in the U87 human glioblastoma cell line, and long-term inhibition of VEGF induces expression of 
YKL-40 (potentially as a compensatory response, i.e. 'angiogenic rebound') [9, 11-17]. Surprisingly, shRNA knockdown of YKL-40 in tumor-derived mural-like cells (GSDCs) also increased VEGF expression and secretion [18]. These apparently contradictory results could be explained by tumor heterogeneity and cell diversity, different models with varying YKL-40 and VEGF expression, and a compensatory increase in VEGF as a result of long-term YKL-40 blockade in shRNA YKL40 cells [18]. Irradiation of U87 cells increases YKL-40 expression [12, 19] and inhibition of YKL-40 enhances U87 cell death in response to irradiation [9]. In vivo, inhibition of YKL-40 in xenografted mice decreases angiogenesis, tumor formation, and metastasis in various tumor models $[9,12]$. Of note, the expression of VEGF and YKL-40 are correlated in both xenografted mice and human glioblastoma samples [12]. Combination therapy with irradiation and anti-YKL-40 neutralizing antibody in xenografted glioblastoma tumor models resulted in decreased tumor growth, reduced tumor vascularization, and increased survival compared with monotherapy [14].

YKL-40 mRNA and protein expression increase with glioma grade and are higher in glioblastoma than in astrocytic- and oligodendroglial tumors [1, 2, 19-28]. In patients with glioblastoma, high YKL-40 expression in glioma cells is associated with poor response to radiotherapy (RT) and a shorter time to disease progression and death [14-17, 20, 21, 28]. YKL-40 is part of a 9-gene paraffin tissue-based expression panel that predicts survival in patients with glioblastoma [29]. Patients with epidermal growth factor receptor (EGFR) variant III-negative/YKL-40-negative tumors have a better prognosis than other tumor subtypes $[25,30]$. It has also been shown that YKL-40 silencing in glioblastoma cells impairs proliferation, neurosphere formation, and their ability to induce endothelial cell migration [31].

In $55 \%$ to $75 \%$ of patients with glioblastoma, plasma YKL-40 is elevated compared with healthy subjects [32-34]. Iwamoto et al. showed that serum YKL40 is lower in patients with glioblastoma and anaplastic gliomas without radiographic disease versus those with radiographic disease [33]. An increase in serum YKL40 after surgery was also independently associated with short survival times in patients with glioblastoma or newly diagnosed anaplastic glioma [34].

Bevacizumab is a humanized monoclonal antibody directed against VEGF-A. Bevacizumab is often used as salvage therapy for patients with glioblastoma, either as monotherapy or in combination with different chemotherapy regimens [35]. A substantial proportion of patients appear to benefit from bevacizumab in this setting, and identifying this patient subgroup is an unmet need to date. In the AVAglio study, patients with newly diagnosed glioblastoma treated with RT and temozolomide (TMZ) in combination with bevacizumab had improved progression-free survival (PFS), but not overall survival (OS), compared with patients treated with RT/TMZ and placebo [36]. A similarly designed study confirmed the lack of OS benefit for bevacizumab in the first-line setting [37].

Objective response to bevacizumab has been correlated with improved OS in the recurrent setting [38], indicating that specific subgroups of patients may obtain a survival benefit from bevacizumab. Finding biomarkers that may identify patients eligible for bevacizumab treatment is therefore highly relevant. Based on the hypothesis that YKL-40 levels in blood and tumor correlate, and that low YKL-40 enhances the effect of bevacizumab (VEGF neutralization), we tested the hypothesis that patients in AVAglio with low YKL-40 plasma concentrations will derive a greater benefit from bevacizumab than patients with higher YKL-40 plasma concentrations, due to the proposed interaction between VEGF, YKL-40, and tumor angiogenesis [11-18].

\section{RESULTS}

The biomarker-evaluable population comprised 279 patients treated with bevacizumab plus RT/TMZ and 284 patients treated with placebo plus RT/TMZ. Patient characteristics were comparable between the biomarkerevaluable and intent-to-treat (ITT) populations (Table 1). The first quartile (Q1), median, and third quartile (Q3) of raw plasma YKL-40 levels at baseline were $39 \mathrm{ng} / \mathrm{mL}, 65$ $\mathrm{ng} / \mathrm{mL}$, and $109 \mathrm{ng} / \mathrm{mL}$, respectively. The corresponding values for age-corrected percentile of normal plasma YKL-40 were 29th, 59th, and 89th percentiles. Raw- and age-corrected levels of plasma YKL-40 in the placebo compared with the bevacizumab cohort at baseline were: median $70 \mathrm{ng} / \mathrm{mL}$ versus $60 \mathrm{ng} / \mathrm{mL}(p=0.02)$, and median percentile 70 th versus 59 th $(p=0.02)$, respectively.

\section{Baseline plasma YKL-40 and patient characteristics}

Baseline plasma YKL-40 levels were higher in patients with poor World Health Organization (WHO) performance status (PS) and in patients who did not have a complete tumor resection (Table 2). Baseline plasma YKL-40 did not differ significantly between molecular subtypes.

\section{Elevated baseline plasma YKL-40 and prognosis}

Fifty-six patients (10\%) had elevated plasma YKL40 (> 90th percentile of normal) at baseline, which was an independent predictor of shorter PFS and OS (Table $3)$. The estimated impact of elevated baseline YKL40 (PFS hazard ratio [HR] 1.84 and OS HR 1.94) was comparable to the impact of poor WHO PS and nonmethylated O-6-methylguanine-DNA methyltransferase gene promoter. 
Table 1: Comparison of clinical and biomarker-evaluable cohorts

\begin{tabular}{|c|c|c|c|}
\hline & $\begin{array}{c}\text { Total trial } \\
\text { Cohort }(n=921), n(\%)\end{array}$ & $\begin{array}{c}\text { Biomarker-evaluable } \\
\text { Cohort }(n=563), n(\%)\end{array}$ & $p^{\mathrm{a}}$ \\
\hline Gender & & & 0.91 \\
\hline Female & $341(37)$ & $206(37)$ & \\
\hline Male & $580(63)$ & $357(63)$ & \\
\hline Age & & & 0.85 \\
\hline$\leq 65$ years & $721(78)$ & $438(78)$ & \\
\hline$>65$ years & $200(22)$ & $125(22)$ & \\
\hline Race & & & 0.72 \\
\hline Non-white & $89(10)$ & $51(9)$ & \\
\hline White & $832(90)$ & $512(91)$ & \\
\hline WHO PS & & & 0.20 \\
\hline 0 & $465(50)$ & $304(54)$ & \\
\hline 1 & $455(49)$ & $258(46)$ & \\
\hline$M G M T$ gene promoter status & & & 0.39 \\
\hline Methylated & 237 (26) & $142(25)$ & \\
\hline Non-methylated & $461(50)$ & $295(52)$ & \\
\hline Missing & $223(24)$ & $126(22)$ & \\
\hline Type of surgery & & & 0.22 \\
\hline Biopsy only & $104(11)$ & $52(9)$ & \\
\hline Partial resection & $433(47)$ & $284(50)$ & \\
\hline Complete resection & $384(42)$ & $227(40)$ & \\
\hline Corticosteroid use at baseline & & & 0.63 \\
\hline$<2 \mathrm{mg}$ & $522(57)$ & $327(58)$ & \\
\hline$\geq 2 \mathrm{mg}$ & $395(43)$ & $232(41)$ & \\
\hline Missing & $4(<1)$ & $4(<1)$ & \\
\hline Smoking status & & & 0.75 \\
\hline Current smoker & $120(13)$ & $65(12)$ & \\
\hline Never smoker & $470(51)$ & $292(52)$ & \\
\hline Past smoker & $330(36)$ & $205(36)$ & \\
\hline
\end{tabular}

${ }^{a}$ Fisher's exact test. Baseline characteristics with more than two levels were combined to compare the largest subgroup against all others.

MGMT = O-6-methylguanine-DNA methyltransferase.

\section{Baseline plasma YKL-40 and bevacizumab efficacy}

Bevacizumab was associated with longer PFS in patients with baseline plasma YKL-40 both below and above the lowest quartile (Q1). The PFS HR was improved in patients with baseline plasma YKL-40 below Q1 (Table 4), relative to the PFS benefit seen for patients with higher baseline plasma YKL-40. The PFS HR was 0.37 (95\% confidence interval [CI]: $0.25-0.55$ ) for patients with YKL40 levels $\leq$ Q1, and 0.71 (95\% CI: 0.57-0.87) for patients with YKL-40 levels $>$ Q1. The OS HR was comparable between the subgroups, with overlapping CIs: OS HR was
0.69 (95\% CI: 0.44-1.09) for patients with YKL-40 levels $\leq$ Q1 and 0.88 (95\% CI: 0.68-1.13) for patients with YKL40 levels $>$ Q1. The PFS and OS Kaplan-Meier curves according to $\mathrm{YKL}-40$ level $\leq \mathrm{Q} 1$ versus $>\mathrm{Q} 1$ are shown in Figure 1. In a multivariate analysis with correction for other baseline characteristics, the interaction between YKL-40 level with Q1 as cut off and bevacizumab treatment was not significant ( $p=0.24$ for PFS and $p=0.32$ for OS).

When all samples were combined, the relative change in plasma YKL-40 level from baseline to second cycle, or from baseline to the end of combination treatment, was not correlated with bevacizumab efficacy (Supplementary Figure 1, available online only). 
For patients with the proneural subtype of glioblastoma, there was a trend for improved PFS HR with low (cut off Q1) versus high plasma YKL-40 levels ( $>$ Q1), although CIs overlapped: PFS HR $0.41(95 \%$ CI: 0.13-1.28) versus 0.80 (95\% CI: 0.45-1.40). A less pronounced trend was noted for OS HR in patients with the proneural subtype of glioblastoma: HR 0.50 (95\% CI: 0.17-1.45) versus OS HR 0.69 (95\% CI: 0.39-1.24), for $\leq \mathrm{Q} 1$ versus $>\mathrm{Q} 1$, respectively. No correlation between YKL-40 levels and bevacizumab efficacy was noted in patients with proliferative and mesenchymal glioblastoma subtypes (Table 5). The sample size for these calculations was very small, as evidenced by the wide CIs.

\section{Plasma YKL-40 during treatment and at progression}

Median plasma YKL-40 levels did not change greatly during treatment or follow up (Supplementary
Figure 2, available online only) and no apparent difference was noted in temporal YKL-40 levels between the placebo and bevacizumab cohorts. However, plasma YKL-40 was numerically lower at the time of progression compared with baseline, although the difference was not extensive (Supplementary Figure 3, available online only).

\section{DISCUSSION}

To our knowledge, this is the first large prospective/ retrospective biomarker study to investigate the prognostic and predictive value of plasma YKL-40 in patients with glioblastoma who received bevacizumab. Based on evidence suggesting a pro-angiogenic role of YKL-40 and interaction with VEGF [18], we hypothesized that low levels of plasma YKL-40 could be predictive of greater clinical benefit from anti-VEGF treatment. Based on raw plasma concentrations of YKL-40 fitted to age-corrected percentiles using the established normal YKL-40 level in

A

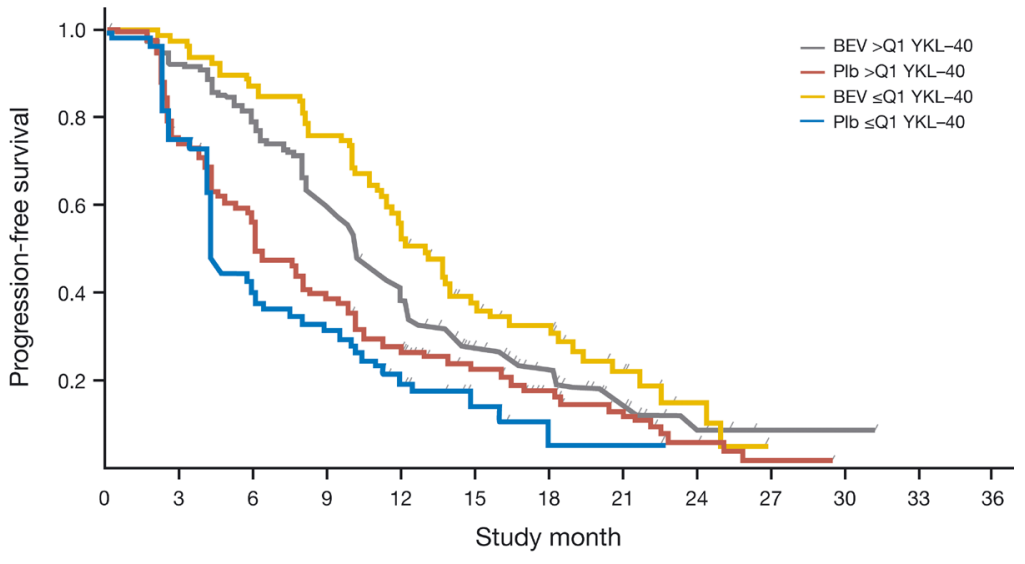

No. at risk BEV $>$ Q1 $Y K L-40$ $P E>Q 1 Y K L-40$ $P$ Q

$\begin{array}{rrrrrrrrrrrrr}200 & 182 & 155 & 117 & 76 & 43 & 28 & 10 & 4 & 1 & 1 & 0 & 0 \\ 79 & 77 & 69 & 60 & 42 & 24 & 19 & 8 & 3 & 0 & 0 & 0 & 0 \\ 222 & 163 & 115 & 83 & 56 & 40 & 26 & 16 & 5 & 1 & 0 & 0 & 0 \\ 62 & 46 & 24 & 19 & 11 & 4 & 1 & 1 & 0 & 0 & 0 & 0 & 0\end{array}$

B

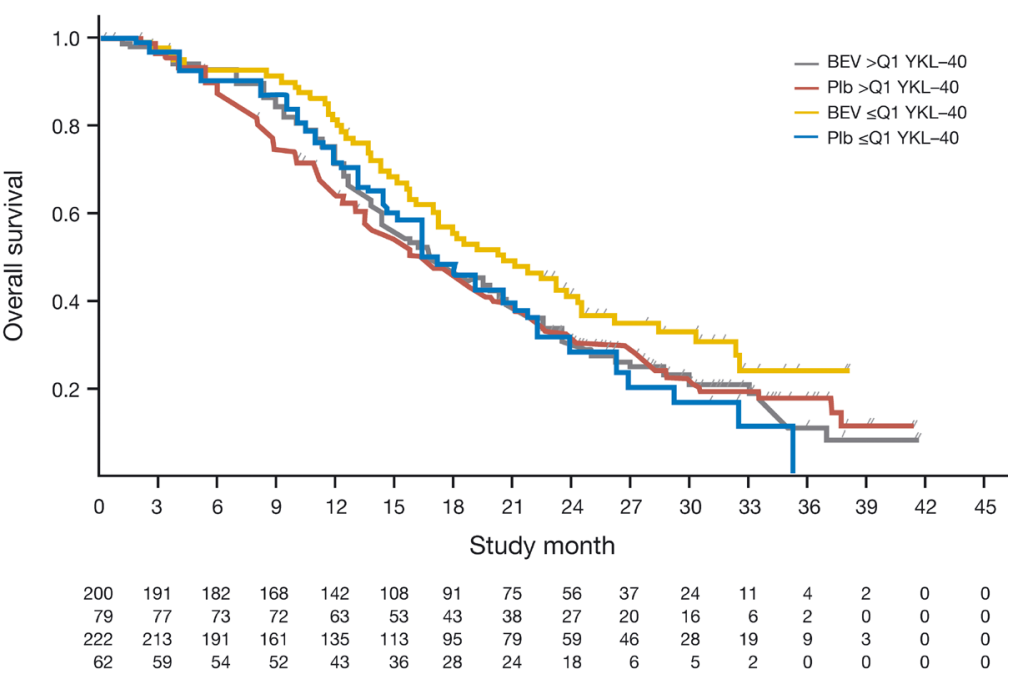

Figure 1: Kaplan-Meier survival curves for (A) progression-free survival and (B) overall survival, according to baseline plasma YKL-40 levels. BEV, bevacizumab; Plb, placebo; Q1, lowest quartile of plasma YKL-40 levels. 


\begin{tabular}{|c|c|c|c|c|}
\hline & \multicolumn{2}{|c|}{ YKL-40, ng/mL } & \multicolumn{2}{|c|}{ 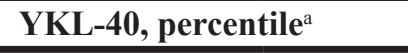 } \\
\hline & Median & $p^{\mathrm{b}}$ & Median & $p^{\mathbf{b}}$ \\
\hline Gender & & 0.40 & & 0.28 \\
\hline Female & 62 & & 64 & \\
\hline Male & 67 & & 67 & \\
\hline Age & & $<0.0001$ & & 0.07 \\
\hline$\leq 65$ years & 57 & & 64 & \\
\hline$>65$ years & 98 & & 73 & \\
\hline Race & & 0.14 & & 0.24 \\
\hline Non-white & 90 & & 78 & \\
\hline White & 64 & & 64 & \\
\hline WHO PS & & $<0.0001$ & & 0.001 \\
\hline 0 & 53 & & 56 & \\
\hline 1 & 78 & & 73 & \\
\hline Type of surgery & & 0.03 & & 0.0496 \\
\hline Biopsy only & 65 & & 64 & \\
\hline Partial resection $^{\mathrm{c}}$ & 69 & & 70 & \\
\hline Complete resection & 55 & & 60 & \\
\hline Smoking status & & 0.31 & & 0.93 \\
\hline Current smoker & 57 & & 60 & \\
\hline Never smoker & 63 & & 65 & \\
\hline Past smoker & 70 & & 67 & \\
\hline Molecular subtype $^{\mathrm{d}}(n=305)$ & & 0.49 & & 0.41 \\
\hline Proneural & 67 & & 61 & \\
\hline Mesenchymal & 70 & & 70 & \\
\hline Proliferative & 61 & & 63 & \\
\hline
\end{tabular}

aPercentile of YKL-40 according to the established normal YKL-40 level in healthy individuals [39].

${ }^{\mathrm{b}} p$ value from Mann-Whitney $\mathrm{U}$ test for two groups or Kruskal-Wallis test for $>2$ groups comparing biomarker levels across the groups.

'Partial resection meant that some extent of tumor debulking was undertaken but macroscopically visible tumor was left behind. This should be contrasted with either diagnostic biopsy only or removal of all visible tumor (complete resection). Since patients with partial resections have larger tumor burdens, higher levels of YKL-40 are to be expected.

${ }^{\mathrm{d}}$ Molecular subtype as defined in the study by Philips et al. 2006 [24].

healthy individuals [39], we report a greater numerical median PFS benefit with bevacizumab in patients with baseline plasma YKL-40 $\leq$ Q1 (below the 29th percentile of normal). We chose to divide the samples by quartiles of plasma YKL-40 levels instead of using a continuous scale because we did not expect the predictive value of plasma YKL-40 to be a continuous phenomenon. This was supported by the finding that patients with plasma YKL40 above Q3 had a HR for bevacizumab versus placebo that was very similar to the HR for patients with plasma YKL-40 between Q1 and the median.

Using Q1 as a cut off in the subset of patients with available molecular subtyping data, we saw the same trend for an improved PFS HR in patients with baseline plasma
YKL-40 $\leq$ Q1, but only in patients with the proneural subtype of glioblastoma. Although the results of this subgroup analysis are based on a small number of patients, this finding is encouraging, since these patients may be the ones who derive most benefit from front-line bevacizumab [40].

The differences observed were larger for PFS than for OS, which may have been confounded by second-line cross-over to bevacizumab in the placebo group (common in this study) [36]. However, cross-over did not influence the magnitude of bevacizumab benefit in patients with the proneural subtype of glioblastoma. In the present analysis, molecular subclasses were defined according to Phillips et al. [24], but other classifications exist [2, 41] and 
Table 3: Elevated baseline plasma YKL-40 and prognosis - multivariate analysis

\begin{tabular}{|c|c|c|c|}
\hline \multirow[t]{2}{*}{ Progression-free survival ${ }^{a}$} & \multirow[b]{2}{*}{ HR } & \multirow[b]{2}{*}{$95 \%$ CI } & \multirow[b]{2}{*}{$p$} \\
\hline & & & \\
\hline Treatment: BEV versus $\mathrm{Pl}^{\mathrm{b}}$ & 0.60 & $0.48-0.76$ & $<0.0001$ \\
\hline YKL-40 level: elevated versus normal ${ }^{\text {b }}$ & 1.84 & $1.20-2.80$ & 0.0047 \\
\hline Age, per year increase & 1.02 & $1.00-1.03$ & 0.018 \\
\hline Race: white versus non-white & 1.61 & $1.12-2.32$ & 0.011 \\
\hline WHO performance status: 0 versus 1 to 2 & 0.69 & $0.55-0.87$ & 0.0013 \\
\hline MGMT: methylated versus non-methylated & 0.47 & $0.37-0.61$ & $<0.0001$ \\
\hline Type of surgery: biopsy versus complete/partial resection & 0.45 & $0.25-0.79$ & 0.0058 \\
\hline \multirow[t]{2}{*}{ Overall survival $^{a}$} & & & \\
\hline & HR & $95 \% \mathrm{CI}$ & $p$ \\
\hline Treatment: BEV versus Plb & 0.94 & $0.74-1.20$ & 0.63 \\
\hline YKL-40 level: elevated versus normal ${ }^{\mathrm{b}}$ & 1.94 & $1.23-3.06$ & 0.0042 \\
\hline Age, per year increase & 1.02 & $1.00-1.04$ & 0.011 \\
\hline Race: white versus non-white & 1.74 & $1.16-2.61$ & 0.0076 \\
\hline WHO PS: 0 versus 1 to 2 & 0.66 & $0.52-0.84$ & 0.0007 \\
\hline$M G M T$ : methylated versus non-methylated & 0.39 & $0.29-0.51$ & $<0.0001$ \\
\hline Corticosteroid use at baseline: $<2 \mathrm{mg}$ versus $\geq 2 \mathrm{mg}$ & 0.75 & $0.59-0.95$ & 0.019 \\
\hline
\end{tabular}

${ }^{a}$ Only significant variables are shown. The following variables were included in the multivariate model but were not significantly associated with either endpoint: gender, Mini-Mental State Examination score, delay between surgery and subsequent treatment, primary versus secondary glioblastoma, enzyme-inducing anti-epileptic drug use at baseline, and confirmation of glioblastoma histology (yes/no).

${ }^{\mathrm{b}} \mathrm{Cut}-\mathrm{off}$ used for the definition of elevated plasma YKL-40 was the 90th percentile of normal [39].

$\mathrm{BEV}=$ bevacizumab; MGMT = O-6-methylguanine-DNA methyltransferase; $\mathrm{Plb}=$ placebo.

different subtypes have been found within the same tumor. This intra- and inter-tumor heterogeneity in glioblastoma complicates the analysis of potential correlations between molecular subtype and biomarkers like YKL-40 [41] and a more advanced subtyping could strengthen the use of YKL-40 as a biomarker for bevacizumab response. YKL40 expression is a key feature of the mesenchymal glioma subtype and is also found in proneural tumors, where it has been located in tumor cells associated with blood vessels. In the description of the molecular sub-classification, Phillips et al. reported that eight of 26 matched tumors changed subtype at recurrence; seven of these to the mesenchymal subtype [24]. Depending on the significance of YKL40 leakage from tumor tissue to systemic circulation and intratumoral heterogeneity, our results could imply that patients with proneural tumors and low plasma YKL-40 may have a better prognosis because neither systemic- nor tumor-related YKL-40 is affecting tumor growth or immune functions. To our knowledge, only Kazakova et al. [42] have described both tumor and serum YKL-40 in patients with glioblastoma $(n=14)$ and suggested that serum YKL40 correlated positively with tissue YKL-40 expression, although it was not clear how this analysis was performed.

In patients with chemotherapy-refractory ovarian cancer treated with single-agent bevacizumab, low-to- normal plasma YKL-40 at baseline was associated with longer PFS and OS suggesting that plasma YKL-40 could be a predictive biomarker for bevacizumab in several tumor types [43].

Ninety percent of patients had normal plasma YKL$40(<90$ th percentile of normal $)$ at baseline in the current study, which could be a reflection of the low tumor burden in these newly diagnosed patients. We validated the previously reported negative prognostic impact of having an elevated plasma YKL-40 at baseline. We did not find any predictive impact of change in plasma YKL-40 during treatment, but the power for this analysis was low.

Loss of blood-brain barrier integrity with ensuing changes in trans- and para-cellular transport is a characteristic associated with high-grade gliomas $[44,45]$ and is used to assess therapeutic response. In glioblastoma- and glioblastoma/oligodendroglioma-mouse models, weekly magnetic resonance imaging (MRI) scans showed increased blood-brain barrier disruption, which was incomplete only in the glioblastoma/ oligodendroglioma model [45]. It is possible that this heterogeneous breakdown of the blood-brain barrier in glioblastoma releases variable amounts of YKL-40 into the circulation, making it difficult to interpret plasma YKL-40 as a biomarker, compared with cancers outside 
Table 4: Baseline plasma YKL-40 level and bevacizumab efficacy

\begin{tabular}{|c|c|c|c|c|c|c|}
\hline \multicolumn{7}{|c|}{ Progression-free survival } \\
\hline \multirow[b]{2}{*}{ YKL-40 level $^{\mathrm{a}}$} & \multicolumn{2}{|c|}{ Plb + RT/TMZ } & \multicolumn{2}{|c|}{ BEV+ RT/TMZ } & \multirow[b]{2}{*}{ HR } & \multirow[b]{2}{*}{$95 \% \mathrm{CI}$} \\
\hline & Patients, $n$ & $\begin{array}{l}\text { Median, } \\
\text { months }\end{array}$ & Patients, $n$ & $\begin{array}{l}\text { Median, } \\
\text { months }\end{array}$ & & \\
\hline$\leq \mathrm{Q} 1$ & 62 & 4.2 & 79 & 12.9 & 0.37 & $0.25-0.55$ \\
\hline$>$ Q1 to $\leq$ Median & 70 & 6.5 & 71 & 10.0 & 0.63 & $0.44-0.91$ \\
\hline$>$ Median to $\leq$ Q3 & 71 & 7.8 & 70 & 10.2 & 0.85 & $0.58-1.24$ \\
\hline$>$ Q3 & 81 & 5.7 & 59 & 10.0 & 0.65 & $0.45-0.94$ \\
\hline$>\mathrm{Q} 1$ & 222 & 6.1 & 200 & 10.0 & 0.71 & $0.57-0.87$ \\
\hline \multicolumn{7}{|l|}{ Overall survival } \\
\hline & \multicolumn{2}{|c|}{ Plb + RT/TMZ } & \multicolumn{2}{|c|}{ BEV+ RT/TMZ } & & \\
\hline YKL-40 level $^{a}$ & Patients, $n$ & $\begin{array}{l}\text { Median, } \\
\text { months }\end{array}$ & Patients, $n$ & $\begin{array}{l}\text { Median, } \\
\text { months }\end{array}$ & HR & $95 \%$ CI \\
\hline$\leq \mathrm{Q} 1$ & 62 & 16.6 & 79 & 19.1 & 0.69 & $0.44-1.09$ \\
\hline$>$ Q1 to $\leq$ Median & 70 & 17.5 & 71 & 17.6 & 0.83 & $0.53-1.30$ \\
\hline$>$ Median to $\leq$ Q3 & 71 & 18.1 & 70 & 16.8 & 1.05 & $0.67-1.65$ \\
\hline$>\mathrm{Q} 3$ & 81 & 13.4 & 59 & 15.4 & 0.85 & $0.56-1.29$ \\
\hline$>\mathrm{Q} 1$ & 222 & 15.8 & 200 & 16.8 & 0.88 & $0.68-1.13$ \\
\hline
\end{tabular}

aPercentile of YKL-40 according to the established normal YKL-40 level in healthy individuals [39].

$\mathrm{BEV}=$ bevacizumab; Plb = placebo; $\mathrm{Q} 1$ to Q3 = first to third quartile of age-corrected YKL-40 levels.

Table 5: Baseline plasma YKL-40 and bevacizumab efficacy by molecular subtype ${ }^{a}$

\begin{tabular}{lccccc}
\hline Plasma YKL-40 level $^{\mathbf{b}}$ & $\boldsymbol{n}$ & PFS HR & $\mathbf{9 5 \%} \mathbf{C I}$ & OS HR & $\mathbf{9 5 \%}$ CI \\
\hline Proneural & & & & & \\
$\leq$ Q1 & 21 & 0.41 & $0.13-1.28$ & 0.50 & $0.17-1.45$ \\
> Q1 & 63 & 0.80 & $0.45-1.40$ & 0.69 & $0.39-1.24$ \\
Proliferative & & & & & \\
$\leq$ Q1 & 20 & 0.56 & $0.21-1.51$ & 1.05 & $0.40-2.72$ \\
> Q1 & 59 & 0.55 & $0.32-0.97$ & 0.91 & $0.51-1.62$ \\
Mesenchymal & & & & & \\
$\leq$ Q1 & 36 & 0.58 & $0.27-1.23$ & 1.01 & $0.47-2.20$ \\
> Q1 & 106 & 0.64 & $0.4-0.97$ & 1.10 & $0.71-1.70$ \\
\hline
\end{tabular}

${ }^{a}$ Molecular subtype as defined in the study by Philips et al. 2006 [24].

${ }^{b}$ Percentile of YKL-40 according to the established normal YKL-40 level in healthy individuals [39].

the central nervous system. A comparison of contrastenhancement and perfusion on MRI and the corresponding plasma YKL-40 levels could further elucidate this subject. It would have been relevant to compare plasma YKL-40 levels with tumor tissue YKL-40 expression, measured using immunohistochemistry, but we did not have access to tissue samples in this study.

Among the strengths of this study was the large number of plasma samples collected $(n=563)$, although, some subgroup numbers were low. Furthermore, the samples were collected prospectively as part of a randomized, placebo-controlled trial and we tested a prespecified hypothesis that had a biologic rationale.
Moreover, a trend for a predictive effect of plasma YKL-40 was seen only in the proneural molecular subtype, which has previously been suggested to derive most benefit from bevacizumab. Important limitations also exist; for example, the test for interaction between bevacizumab effect and baseline plasma YKL-40 with Q1 as a cut off was not significant in the multivariate analysis. This would be expected if the effect of YKL-40 was isolated to a smaller subset of patients, e.g. the proneural subset. It also suggests that baseline plasma YKL-40 alone is not a strong enough biomarker to accurately predict bevacizumab benefit. Furthermore, we did not provide an independent validation of our findings, and even though 
we prespecified a hypothesis about low plasma YKL-40 levels predicting a greater bevacizumab benefit, we did not lock a cut-off point before undertaking the study.

In conclusion, these results represent an encouraging first foray into the use of plasma YKL-40 as a biomarker in patients with glioblastoma treated with bevacizumab. Further studies are needed to investigate plasma YKL-40 in patients with cancer given an anti-angiogenic agent, to validate the positive predictive effect of low-to-normal plasma YKL-40 levels, and to determine the optimal cut-off point. It would also be of interest to investigate the doubleinhibition of VEGF and YKL-40 for the treatment of cancer.

\section{MATERIALS AND METHODS}

\section{Ethics statement}

The protocol was approved by the applicable independent ethics committees and institutional review boards. All clinical investigations were conducted according to the principles expressed in the Declaration of Helsinki and according to national and international guidelines and were approved by the authors' institutional review board. All patients provided written informed consent.

\section{Patients}

AVAglio was a randomized, double-blind, placebocontrolled trial (NCT00943826; https://clinicaltrials.gov/ ct $2 /$ show/NCT00943826) [36]. Full methods, including patient randomization, treatment, and follow-up, are published [36]. Patients with newly diagnosed glioblastoma received bevacizumab or placebo in combination with standard post-surgical RT/TMZ. Eligibility criteria included a WHO PS of $\leq 2$, adequate healing of the operation site, and preserved organ function. Patients were excluded if they had a recent symptomatic intracranial hemorrhage, prior brain RT, prior glioblastoma treatment, recent intracranial abscess, or a serious non-healing wound. After surgical resection or biopsy, patients received RT consisting of 2-Gy fractions 5 days per week for 6 weeks, concurrent with daily oral TMZ $\left(75 \mathrm{mg} / \mathrm{m}^{2}\right)$, in combination with intravenous bevacizumab $(10 \mathrm{mg} / \mathrm{kg})$ or placebo every 2 weeks. Following RT/TMZ and a 4-week treatment break, patients received maintenance treatment with TMZ (150 $\mathrm{mg} / \mathrm{m}^{2} /$ day on days 1 to 5 during the first 4-week cycle and $200 \mathrm{mg} / \mathrm{m}^{2} /$ day on days 1 to 5 during the following cycles) and intravenous bevacizumab $(10 \mathrm{mg} / \mathrm{kg})$ or placebo every 14 days for six 4-week cycles. Subsequently, patients without progression were treated with bevacizumab (15 $\mathrm{mg} / \mathrm{kg}$ ) or placebo as monotherapy every 3 weeks until progression or unacceptable toxicity [36].

The determination of progression was based on a combination of MRI, clinical assessment, and corticosteroid use, as previously described [36]. Coprimary endpoints were PFS, defined as time from randomization to progression or death from any cause, and $\mathrm{OS}$, defined as time from randomization to death from any cause.

\section{Blood sampling and plasma YKL-40 analysis}

The first plasma sample (baseline) was drawn within 29 to 48 days after surgery and before treatment with RT/TMZ and bevacizumab/placebo. Thereafter, plasma samples were drawn at regular intervals during treatment and at the time of disease progression.

Blood samples were centrifuged within 2 hours at $3,000 \times g$ for 10 minutes at room temperature. Plasma was transferred into cryotubes and stored at $-80^{\circ} \mathrm{C}$. Plasma concentration of YKL-40 was determined in duplicate using a commercial enzyme-linked immunosorbent assay (Quidel, San Diego, California). The detection limit was $20 \mathrm{ng} / \mathrm{mL}$, the intra-assay coefficient of variation $(\mathrm{CV})$ was $<5 \%$, and the inter-assay CV was $<6 \%[39,46]$. Plasma YKL-40 was determined at the Department of Medicine, Herlev University Hospital, Denmark and investigators were blinded to the treatment arms and clinical data.

The reference intervals for plasma YKL-40 were determined in 3,130 healthy subjects $(1,837$ women, 1,293 men) aged 21 to 84 years from the Danish general population (part of the Copenhagen City Heart Study) [39]. These subjects had no known disease at the time of blood sampling from 1991 to 1994, and remained healthy and alive during the 16-year follow-up period. The median plasma YKL-40 concentration in these 3,130 healthy subjects was $40 \mathrm{ng} / \mathrm{mL}$.

\section{Molecular subtypes of glioblastoma}

Three molecular subtypes of glioblastoma have been identified by gene expression analysis: proneural, proliferative, and mesenchymal [24]. Using tumor samples from the AVAglio trial, Sandmann et al. found that the molecular subtype of glioblastoma could be predictive for bevacizumab efficacy [40]. Therefore, data regarding molecular subtypes were included in our analyses.

\section{Statistical analysis}

Raw plasma concentrations of YKL-40 were transformed to age-corrected percentiles using the established normal YKL-40 level in healthy individuals [39]. All YKL-40 levels referred to are percentiles of normal level unless explicitly called 'raw'. Comparisons were made between quartiles of YKL-40 levels ( $>$ Q1 vs $\leq$ Q1); and between normal ( $\leq 90$ th percentile) and elevated ( $>90$ th percentile) YKL-40 levels. The selection of Q1 as a cut off was supported by the plot shown Supplementary Figure 4 (available online only).

Fisher's exact test was used to compare baseline characteristics between the biomarker evaluable 
population and the ITT population. The Mann-Whitney $U$ test (for two groups) or Kruskal-Wallis test (for $>2$ groups) was used to compare YKL-40 levels by baseline patient characteristics. Kaplan-Meier methodology was applied for time-to-event endpoints. The associations between plasma YKL-40 level and PFS and OS were tested using univariate and multivariate Cox regression. All results were reported in accordance with REMARK guidelines [47].

\section{Author contributions}

Mogens K. Boisen and Julia S. Johansen were involved in the conception and design of the study. All authors were involved in the collection and assembly of data, data analysis, and interpretation and manuscript writing. All authors provided final approval of the manuscript for publication.

\section{ACKNOWLEDGMENTS}

We would like to thank the biomedical laboratory scientists Tonni Løve Hansen, Dorthe Mogensen, and Ulla Kjærulff-Hansen for determination of plasma YKL-40. The patients are thanked for their willingness to participate in the AVAglio trial. We would also like to thank Carlos Bais for his support of this manuscript. Editorial assistance, in the form of formatting and editing, was provided by Gardiner-Caldwell Communications and funded by F. Hoffmann-La Roche Ltd.

\section{CONFLICTS OF INTEREST}

Mogens K. Boisen reports research funding from Roche/Genentech, and being a biomarker advisory board member for Roche Denmark. Camilla B. Holst reports no conflicts. Julia S. Johansen reports honoraria and research funding from, and being a biomarker advisory board member for, Roche Denmark. Julia S. Johansen is a coinventor on patents related to YKL-40. Nicola Consalvo is an employee of Roche. Olivier Chinot is a consultant for Roche.

\section{FUNDING}

The AVAglio trial was sponsored by F. Hoffmann-La Roche Ltd. This analysis of AVAglio data was supported by a grant from F. Hoffmann-La Roche Ltd/Genentech given to Mogens K. Boisen and Julia S. Johansen to cover plasma YKL-40 analysis expenses.

\section{REFERENCES}

1. Tanwar MK, Gilbert MR, Holland EC. Gene expression microarray analysis reveals YKL-40 to be a potential serum marker for malignant character in human glioma. Cancer Res. 2002; 62:4364-4368.

2. Verhaak RG, Hoadley KA, Purdom E, Wang V, Qi Y, Wilkerson MD, Miller CR, Ding L, Golub T, Mesirov JP, Alexe G, Lawrence M, O'Kelly M, et al. Integrated genomic analysis identifies clinically relevant subtypes of glioblastoma characterized by abnormalities in PDGFRA, IDH1, EGFR, and NF1. Cancer Cell. 2010; 17:98-110.

3. Schultz NA, Johansen JS. YKL-40 - a protein in the field of translational medicine: a role as a biomarker in cancer patients? Cancers (Basel). 2010; 2:1453-1491.

4. Lee CG, Da Silva C, Dela Cruz CS, Ahangari F, Ma B, Kang MJ, He CH, Takyar S, Elias JA. Role of chitin and chitinase/ chitinase-like proteins in inflammation, tissue remodelling, and injury. Annu Rev Physiol. 2011; 73:479-501.

5. Brøchner CB, Johansen JS, Larsen LA, Bak M, Mikkelsen HB, Byskov AG, Andersen CY, Møllgård K. YKL-40 is differentially expressed in human embryonic stem cells and in cell progeny of the three germ layers. J Histochem Cytochem. 2012; 60:188-204.

6. He CH, Lee CG, Dela Cruz CS, Lee CM, Zhou Y, Ahangari F, Ma B, Herzog EL, Rosenberg SA, Li Y, Nour AM, Parikh CR, Schmidt I, et al. Chitinase 3-like 1 regulates cellular and tissue responses via IL-13 receptor $\alpha 2$. Cell Rep. 2013; 4:830-841.

7. Zhou Y, He CH, Herzoq EL, Peng X, Lee CM, Nguyen TH, Gulati M, Gochuico BR, Gahl WA, Slade ML, Lee CG, Elias JA. Chitinase 3-like-1 and its receptors in HermanskyPudlak syndrome-associated lung disease. J Clin Invest. 2015; 125:3178-3192.

8. Low D, Subramaniam R, Lin L, Aomatsu T, Mizoquchi A, Ng A, DeGruttola AK, Lee CG, Elias JA, Andoh A, MinoKenudson M, Mizoquchi E. Chitinase 3-like 1 induces survival and proliferation of intestinal epithelial cells during chronic inflammation and colitis-associated cancer by regulating S100A9. Oncotarget. 2015; 6:36535-36550. https://doi.org/10.18632/oncotarget.5440.

9. Shao R, Hamel K, Petersen L, Cao QJ, Arenas RB, Bigelow C, Bentley B, Yan W. YKL-40, a secreted glycoprotein, promotes tumor angiogenesis. Oncogene. 2009; 28:4456-4468.

10. Görgens SW, Eckardt K, Elsen M, Tennagels N, Eckel J. Chitinase-3-like protein 1 protects skeletal muscle from $\mathrm{TNF} \alpha$-induced inflammation and insulin resistance. Biochem J. 2014; 459:479-488.

11. Saidi A, Javerzat S, Bellahcene A, De Vos J, Bello L, Castronovo V, Deprez M, Loiseau H, Bikfalvi A, Hagedorn M. Experimental anti-angiogenesis causes upregulation of genes associated with poor survival in glioblastoma. Int $\mathrm{J}$ Cancer. 2008; 122:2187-2198.

12. Faibish M, Francescone R, Bentley B, Yan W, Shao R. A YKL-40 neutralizing antibody blocks tumor angiogenesis and progression: a potential therapeutic agent in cancers. Mol Cancer Ther. 2011; 10:742-751.

13. Francescone RA, Scully S, Faibish M, Taylor SL, Oh D, Moral L, Yan W, Bentley B, Shao R. Role of YKL-40 
in the angiogenesis, radioresistance, and progression of glioblastoma. J Biol Chem. 2011; 286:15332-15343.

14. Shao R. YKL-40 acts as an angiogenic factor to promote tumor angiogenesis. Front Physiol. 2013; 4:122.

15. Shao R, Francescone R, Ngernyuang N, Bentley B, Taylor SL, Moral L, Yan W. Anti-YKL-40 antibody and ionizing irradiation synergistically inhibit tumor vascularization and malignancy in glioblastoma. Carcinogenesis. 2014; 35:373-382.

16. Libreros S, Iraqavarapu-Charyulu V. YKL-40/CHI3L1 drives inflammation on the road of tumor progression. $\mathrm{J}$ Leukoc Biol. 2015; 98:931-936.

17. Iwamoto FM, Hormigo A. Unveiling YKL-40, from serum marker to target therapy in glioblastoma. Front Oncol. 2014; 4:90.

18. Francescone R, Ngernyuang N, Yan W, Bentley B, Shao R. Tumor-derived mural-like cells coordinate with endothelial cells: role of YKL-40 in mural cell-mediated angiogenesis. Oncogene. 2014; 33:2110-2122.

19. Junker N, Johansen JS, Hansen LT, Lund EL, Kristjansen PE. Regulation of YKL-40 expression during genotoxic or microenvironmental stress in human glioblastoma cells. Cancer Sci. 2005; 96:183-190.

20. Nigro JM, Misra A, Zhang L, Smirnov I, Colman H, Griffin C, Ozburn N, Chen M, Pan E, Koul D, Yung WK, Feuerstein BG, Aldape KD. Integrated array-comparative genomic hybridization and expression array profiles identify clinically relevant molecular subtypes of glioblastoma. Cancer Res. 2005; 65:1678-1686.

21. Nutt CL, Betensky RA, Brower MA, Batchelor TT, Louis DN, Stemmer-Rachamimov AO. YKL-40 is a differential diagnostic marker for histologic subtypes of high-grade gliomas. Clin Cancer Res. 2005; 11:2258-2264.

22. Pelloski CE, Mahajan A, Maor M, Chang EL, Woo S, Gilbert M, Colman H, Yang H, Ledoux A, Blair H, Passe S, Jenkins $\mathrm{RB}$, Aldape KD. YKL-40 expression is associated with poorer response to radiation and shorter overall survival in glioblastoma. Clin Cancer Res. 2005; 11:3326-3334.

23. Colin C, Baeza N, Bartoli C, Fina F, Eudes N, Nanni I, Martin PM, Ouafik L, Figarella-Branger D. Identification of genes differentially expressed in glioblastoma versus pilocytic astrocytoma using suppression subtractive hybridization. Oncogene. 2006; 25:2818-2826.

24. Phillips HS, Kharbanda S, Chen R, Forrest WF, Soriano RH, Wu TD, Misra A, Nigro JM, Colman H, Soroceanu L, Williams PM, Modrusan Z, Feuerstein BG, et al. Molecular subclasses of high-grade glioma predict prognosis, delineate a pattern of disease progression, and resemble stages in neurogenesis. Cancer Cell. 2006; 9:157-173.

25. Rousseau A, Nutt CL, Betensky RA, Iafrate AJ, Han M, Ligon KL, Rowitch DH, Louis DN. Expression of oligodendroglial and astrocytic lineage markers in diffuse gliomas: use of YKL-40, ApoE, ASCL1, and NKX2-2. J Neuropathol Exp Neurol. 2006; 65:1149-1156.
26. Pelloski CE, Ballman KV, Furth AF, Zhang L, Lin E, Sulman EP, Bhat K, McDonald JM, Yung WK, Colman H, Woo SY, Heimberger AB, Suki D, et al. Epidermal growth factor receptor variant III status defines clinically distinct subtypes of glioblastoma. J Clin Oncol. 2007; 25:2288-2294.

27. Ducray F, Idbaih A, de Reyniès A, Bièche I, Thillet J, Mokhtari K, Lair S, Marie Y, Paris S, Vidaud M, Hoang-Xuan K, Delattre O, Delattre JY, et al. Anaplastic oligodendrogliomas with 1p19q codeletion have a proneural gene expression profile. Mol Cancer. 2008; 7:41.

28. Salvati M, Pichierri A, Piccirilli M, Floriana Brunetto GM, D'Elia A, Artizzu S, Santoro F, Arcella A, Giangaspero F, Frati A, Simione L, Santoro A. Extent of tumor removal and molecular markers in cerebral glioblastomas: a combined prognostic factors study in a surgical series of 105 patients. J Neurosurg. 2012; 117:204-211.

29. Colman H, Zhang L, Sulman EP, McDonald JM, Shooshtari NL, Rivera A, Popoff S, Nutt CL, Louis DN, Cairncross JG, Gilbert MR, Phillips HS, Mehta MP, et al. A multigene predictor of outcome in glioblastoma. Neuro Oncol. 2010; 12:49-57.

30. Horbinski C, Wang G, Wiley CA. YKL-40 is directly produced by tumor cells and is inversely linked to EGFR in glioblastomas. Int J Clin Exp Pathol. 2010; 3:226-237.

31. Pinet S, Bessette B, Vedrenne N, Lacroix A, Richard L, Jauberteau MO, Battu S, Lalloué F. TrkB-containing exosomes promote the transfer of glioblastoma aggressiveness to YKL-40-inactivated glioblastoma cells. Oncotarget. 2016; 7:50349-50364. https://doi.org/10.18632/ oncotarget. 10387.

32. Hormigo A, Gu B, Karimi S, Riedel E, Panageas KS, Edgar MA, Tanwar MK, Rao JS, Fleisher M, DeAngelis LM, Holland EC. YKL-40 and matrix metalloproteinase-9 as potential serum biomarkers for patients with high-grade gliomas. Clin Cancer Res. 2006; 12:5698-5704.

33. Iwamoto FM, Hottinger AF, Karimi S, Riedel E, Dantis J, Jahdi M, Panageas KS, Lassman AB, Abrey LE, Fleisher M, DeAngelis LM, Holland EC, Hormigo A. Serum YKL-40 is a marker of prognosis and disease status in high-grade gliomas. Neuro Oncol. 2011; 13:1244-1251.

34. Bernadi D, Padoan A, Ballin A, Sartori M, Manara R, Scienza R, Plebani M, Della Puppa A. Serum YKL-40 following resection for cerebral glioblastoma. J Neurooncol. 2012; 107:299-305.

35. Diaz RJ, Ali S, Qadir MG, De La Fuente MI, Ivan ME, Komotar RJ. The role of bevacizumab in the treatment of glioblastoma. J Neurooncol. 2017; 133:455-467.

36. Chinot OL, Wick W, Mason W, Henriksson R, Saran F, Nishikawa R, Carpentier AF, Hoang-Xuan K, Kavan P, Cernea D, Brandes AA, Hilton M, Abrey L, et al. Bevacizumab plus radiotherapy-temozolomide for newly diagnosed glioblastoma. N Engl J Med. 2014; 370:709-722.

37. Gilbert MR, Dignam JJ, Armstrong TS, Wefel JS, Blumenthal DT, Vogelbaum MA, Colman H, Chakravarti 
A, Pugh S, Won M, Jeraj R, Brown PD, Jaeckle KA, et al. A randomized trial of bevacizumab for newly diagnosed glioblastoma. N Engl J Med. 2014; 370:699-708.

38. Prados M, Cloughesy T, Samant M, Fang L, Wen PY, Mikkelsen T, Schiff D, Abrey LE, Yung WK, Paleologos N, Nicholas MK, Jensen R, Vredenburgh J, et al. Response as a predictor of survival in patients with recurrent glioblastoma treated with bevacizumab. Neuro Oncol. 2011; 13:143-151.

39. Bojesen SE, Johansen JS, Nordestgaard BG. Plasma YKL40 levels in healthy subjects from the general population. Clin Chim Acta. 2011; 412:709-712.

40. Sandmann T, Bourgon R, Garcia J, Li C, Cloughesy T, Chinot OL, Wick W, Nishikawa R, Mason W, Henriksson R, Saran F, Lai A, Moore N, et al. Patients with proneural glioblastoma may derive overall survival benefit from the addition of bevacizumab to first-line radiotherapy and temozolomide: retrospective analysis of the AVAglio trial. J Clin Oncol. 2015; 33:2735-2744.

41. Eder K, Kalman B. Molecular heterogeneity of glioblastoma and its clinical relevance. Pathol Oncol Res. 2014; 20:777787.

42. Kazakova MH, Staneva DN, Koev IG, Staikov DG, Mateva N, Timonov PT, Miloshev GA, Sarafian VS. Protein and mRNA levels of YKL-40 in high-grade glioma. Folia Biol (Praha) 2014; 60:261-267.
43. Boisen MK, Madsen CV, Dehlendorf C, Jakobsen A, Johansen JS, Steffensen KD. The prognostic value of plasma YKL-40 in patients with chemotherapy-resistant ovarian cancer treated with bevacizumab. Int J Gynecol Cancer. 2016; 26:1390-1398.

44. Liebner S, Fischmann A, Rascher G, Duffner F, Grote EH, Kalbacher H, Wolburg H. Claudin-1 and claudin-5 expression and tight junction morphology are altered in blood vessels of human glioblastoma multiforme. Acta Neuropathol. 2000; 100:323-331.

45. Leten C, Struys T, Dresselaers T, Himmelreich U. In vivo and ex vivo assessment of the blood brain barrier integrity in different glioblastoma animal models. J Neurooncol. 2014; 119:297-306.

46. Johansen JS, Lottenburger T, Nielsen HJ, Jensen JE, Svendsen MN, Kollerup G, Christensen IJ. Diurnal, weekly, and long-time variation in serum concentrations of YKL40 in healthy subjects. Cancer Epidemiol Biomarkers Prev. 2008; 17:2603-2608.

47. McShane LM, Altman DG, Sauerbrei W, Taube SE, Gion M, Clark GM, Statistics Subcommittee of the NCIEORTC Working Group on Cancer Diagnostics. Reporting recommendations for tumor marker prognostic studies. J Clin Oncol. 2005; 23:9067-9072. 